\title{
Gambaran medication error pada fase prescribing dan administrasi pada pengobatan stroke di IGD Rumah Sakit X di Yogyakarta
}

\author{
Tomi $^{1}$, Akrom ${ }^{2}$, Agnes Jatiningrum ${ }^{3}$ \\ ${ }^{1,2}$ Magister Farmasi Klinis, Universitas Ahmad Dahlan \\ Jl. Prof. Dr. Soepomo,S.H., Janturan, Yogyakarta \\ ${ }^{3}$ RSUD Panembahan Senopati Bantul \\ Jl. Dr. Wahidin Sudirohusodo Bantul,Yogyakarta
}

Submitted: 15-07-2016

Reviewed: 30-11-2016

Accepted: 10-04-2017

\begin{abstract}
ABSTRAK
Stroke merupakan keadaan gawat darurat yang memerlukan penanganan dengan cepat dan tepat di IGD, namun kenyataannya sering dilaporkan kejadian medication error (ME) di IGD. Tujuan penelitian ini adalah menentukan gambaran kejadian ME di IGD rumah sakit X.Telah dilakukan penelitian observasional deskriptif dengan pengambilan data pasien secara prospektif pada bulan Desember 2014 - April 2015 di IGD Rumah Sakit X di Yogyakarta. Didapatkan sebanyak 106 pasien dengan kriteria inklusi subjek adalah pasien dengan diagnosis stroke non hemoragik maupun stroke hemoragik, baik dengan penyakit penyerta maupun tanpa penyakit penyerta. Data yang diperoleh di kaji terhadap kemungkinan terjadinya ME pada fase prescribing dan administrasi (cara pemberian) berdasarkan Persatuan Dokter Spesialis Syaraf Indonesia (PERDOSSI). Pengolahan data dilakukan dengan analisa monovariat untuk mengetahui gambaran karakteristik umum pasien (gambaran demografi), karakteristik klinik pasien serta gambaran kejadian, distribusi dan fase ME. Data gambaran kejadian, distribusi dan fase ME disajikan secara deskriptif (persentase). Hasil dari penelitian ini adalah pasien yang berusia lebih dari 60 tahun sebanyak 67 (63,20\%). Sebanyak 85,80\% pasien didiagnosis stroke non hemoragik dan sisanya sebanyak $14,20 \%$ didiagnosis stroke hemoragik. ME terjadi pada 104 pasien $(98,10 \%)$. Distribusi kejadian ME pada fase prescribing dan administrasi per pasien adalah 28 pasien mengalami satu kejadian ME, 48 pasien mengalami dua kejadian ME, Sebanyak 20 pasien yang mengalami tiga kejadian ME, 8 pasien mengalami empat kejadian ME. Total kejadian medication error yang terjadi sebanyak 216 dari 106 pasien dengan nilai rata-rata 2 kejadian error per pasien. Medication error di fase prescribing sebanyak $98,11 \%$ dan medication error di fase administrasi sebanyak $61,32 \%$.
\end{abstract}

Kata kunci : stroke, geriatri, medication error, prescribing, administrasi.

\begin{abstract}
Stroke is widely known as an emerging disease that which requires quick and precise treatment in the emergency department (ED) of hospital. This study aims to determine the number of ER of Hospital X. An observational study througha prospective analysis of ER was conducted from December 2014 to April 2015. Herein, weobtained a total of 106 patients with inclusion subject criterions,includingpatients with non-hemorrhagic stroke and patients with hemorrhagic stroke diagnosis, where both are either withor without comorbidities.
\end{abstract}

\footnotetext{
Penulis korespondesi:

Tomi

Magister Farmasi Klinis, Universitas Ahmad Dahlan

Jl. Prof. Dr. Soepomo,S.H., Janturan, Yogyakarta 55164

Email: tomi_crb@yahoo.com
} 
Data processing was done through Monovariate analysis to describe the general characteristics of the patients, clinical descriptionof patients, depictionof the incidence, distribution, and ME phase. The description, distribution of the incidence data, and ME phase were presented in percentage subsequently.This study resulted that the number of geriatric patients over than 60 years old were 67 patients (63.20\%). Both patients criterions, who are with the non-hemorrhagic and with the hemorrhagic strokes, were recorded to be $85.80 \%$ and $14.20 \%$, respectively. While, MEs occurred in 104 patients or $98.1 \%$ of all participants. The distributions of MEs in the phases of the prescribing and administration per patient were 28 who experienced once ME incidence, 48 who experienced two times ME incidences, 20 patients who experienced three episodes ME incidences, and 8 patients experienced with four times ME incidences. The total incidences of ME were 216 obtained from the 106 patients with an average value was 2 per patient. Furthermore, MEs in prescribing and administration phases were reported to be $98.11 \%$ and $61.32 \%$, respectively.

Keywords: stroke, geriatric, medication error, prescribing, administration.

\section{PENDAHULUAN}

Stroke merupakan penyakit serebrovaskuler yang menjadi penyebab utama kematian yang sering terjadi di Indonesia. Di pusat-pusat pelayanan neurologi Indonesia jumlah penderita gangguan peredaran darah otak (GPDO) selalu menempati urutan pertama dari seluruh penderita rawat inap (Harsono, 2007).

Di Indonesia menurut Riskesdas 2007 stroke merupakan penyebab kematian pada semua kelompok umur tertinggi dengan proporsi $15,4 \%$, sedangkan pada kelompok umur 55-64 tahun mencapai $26,8 \%$ baik di perkotaan maupun pedesaan dan kasus stroke termuda ditemukan pada kelompok umur 18-24 tahun. Prevalensi stroke di Indonesia sebesar 8,30 per 1000 penduduk dan yang telah didiagnosis oleh tenaga kesehatan adalah 6 per 1000 penduduk (Anonim, 2013).

Adanya penyakit penyerta sebagai faktor risiko pasien stroke mengakibatkan pasien akan sering mengkonsumsi lebih dari dua macam obat. Pengobatan yang seringkali diberikan dalam jenis yang banyak dan saling tumpang tindih dapat berisiko pada ketidakefektifan pengobatan dan kekeliruan yang disebut medication error. Kejadian medication error dibagi dalam empat fase, yaitu fase prescribing (error terjadi pada penulisan resep), fase transcribing (error terjadi pada saat pembacaan resep), fase dispensing (error terjadi pada saat penyiapan hingga penyerahan obat) dan fase administration (error yang terjadi pada proses penggunaan obat) (Cochen, 1991).

Insiden medication error sering sekali terjadi di rumah sakit dengan angka kejadian cukup bervariasi, berkisar antara 3-6,90\% untuk pasien rawat inap (Kohn et.al., 2000). Terjadinya medication error mempengaruhi kepercayaan pasien pada sistem layanan kesehatan dan juga menyebabkan terjadinya peningkatan biaya layanan kesehatan (Anonim ${ }^{a}$ 1993; Kohn et al., 2000). Pada studi prospektif yang dilakukan oleh Perwitasari et al., (2010) di rumah sakit pemerintah di Yogyakarta pada bulan Juni-September 2009 menunjukkan bahwa terjadi medication errors sebanyak 226 resep dari 229 resep yang diteliti antara lain 99,12\% prescribing errors, 3,02\% pharmaceutical errors dan $3,66 \%$ dispensing errors. Tipe dari prescribing error adalah ketidaklengkapan permintaan peresepan (incomplete prescription orders). Peresepan dokter merupakan penyebab umum terjadinya kesalahan (99,12\%). Pharmaceutical errors meliputi overdose dan underdose pemberian obat. Dispensing errors meliputi improper drug preparation dan incomplete atau no drug information.

Studi yang dilakukan pada pasien stroke oleh Mutmainah (2005) menunjukkan bahwa pada studi retrospektif ditemukan adanya kejadian medication error dengan tipe prescribing error (26,09\%), wrong administration technique (68,12\%) dan monitoring error (5,90\%). Penggunaan antibiotik yang kurang tepat ditemukan sebesar $92,31 \%$ dan penanganan hiperglikemi pada stroke yang kurang tepat sebesar 45,45\%. Dari studi prospektif ditemukan kejadian medication error dengan tipe prescribing error (25\%) dan wrong administration technique (75\%). Penggunaan antibiotik yang kurang tepat sebesar $78,60 \%$, penanganan hiperglikemi pada stroke yang kurang tepat sebesar $12,50 \%$, 
dan kejadian efek samping obat sebesar 1,92\%. Dari penelitian tersebut dapat disimpulkan bahwa 49 dari $52(94,23 \%)$ pasien stroke pada bulan Januari-Juli 2004 dan 16 dari $18(88,89 \%)$ pasien stroke pada bulan September-Oktober 2004 mengalami kejadian medication error. Tindakan nyata yang dapat dilakukan untuk mencegah medication error oleh seorang farmasis adalah melakukan skrining resep yang dapat ditinjau dari kelengkapan resep yang meliputi identitas dokter, identitas pasien, nama obat, regimen dosis, serta kelengkapan administratif yang lain (Surat Keputusan Menteri Kesehatan RI Nomor 1027/MENKES/SK/IX/2004).

Pasien yang masuk ke IGD rumah sakit tentunya butuh pertolongan yang cepat dan tepat untuk itu perlu adanya standar dalam memberikan pelayanan gawat darurat sesuai dengan kompetensi dan kemampuan sehingga dapat menjamin suatu penanganan gawat darurat dengan respon time yang cepat dan penanganan yang tepat (Anonim, 2009). Studi yang dilakukan Patanwala (2010) menyatakan 178 medication error terjadi dari 194 pasien di instalasi gawat darurat. Kesalahan terbanyak ada pada fase prescribing $53,90 \%$ dan fase administrasi $34,80 \%$. Stroke murupakan keadaan gawat darurat yang memerlukan penanganan dengan cepat dan tepat. Deteksi dini pada pasien stroke sangat penting untuk menentukan penanganan yang akan dilakukan. Tujuan penelitian ini adalah untuk mengetahui gambaran kejadian medication error pada fase prescribing maupun administrasi sebagai dasar untuk melakukan perbaikan pelayanan di IGD sehingga penelitian ini bertujuan untuk mengetahui gambaran kejadian medication error pada fase prescribing dan administrasi di IGD rumah sakit X.

\section{METODE PENELITIAN}

Penelitian akan dilakukan selama lima bulan pada bulan Desember 2014 - April 2015 di 2 IGD rumah sakit di yogyakarta. Pengumpulan data dilakukan secara prospektif dengan mengambil data pasien stroke yang akan digunakan sebagai sampel penelitian di IGD Rumah Sakit X di Yogyakarta.

a. Kriteria Inklusi Sampel

1) Diagnosis stroke non hemoragik maupun stroke hemoragik, baik dengan penyakit penyerta maupun tanpa penyakit penyerta.

2) Dirawat dalam ruangan IGD di Rumah Sakit $X$ di Yogyakarta pada periode penelitian yaitu selama Desember 2014 - April 2015.

3) Bersedia terlibat sebagai responden dalam penelitian.

b. Kriteria Eksklusi Sampel

1) Pasien stroke yang tidak mendapatkan penanganan di IGD kemudian dirujuk atau meninggal.

Tahap pengumpulan data dimulai dengan melacak pasien-pasien di ruang IGD yang didiagnosis stroke. Setelah mendapatkan pasien yang terdiagnosis stroke, maka dimulai untuk pengambilan data demografi dan riwayat pengobatan pasien stroke di IGD. Jenis data yang digunakan dalam penelitian ini adalah data primer dan sekunder.

Data primer diperoleh melalui interview pada pasien atau keluarga. Interview pada pasien atau keluarga pasien dilakukan untuk menggali informasi yang diperlukan seperti riwayat penyakit dan pola hidup, riwayat pengobatan, keluhan dan kepatuhan pasien dalam meminum obat (jika ada obat yang diminum). Data sekunder dari data rekam medis stroke mulai dari pasien masuk IGD Rumah Sakit hingga keluar dari ruangan IGD. Data sekunder yang diambil dari rekam medis adalah identitas pasien berupa nama, usia, jenis kelamin, alamat, waktu awitan stroke, waktu pasien tiba di Rumah Sakit, diagnosis awal, instruksi atau tindakan pengobatan, profil pengobatan, hasil pemeriksaan hasil laboratorium dan pemeriksaan penunjang lainnya. Data yang diperoleh baik dari data primer maupun dari data sekunder kemudian dituliskan dalam form pengambilan data atau case record form (CRF) yang sudah dibuat oleh peneliti dan telah disahkan oleh komite etik Universitas Ahmad Dahlan (UAD).

Diagnosis dan jenis stroke didasarkan pada diagnosis dokter yang tercatat pada rekam medik dengan atau tanpa data hasil pemeriksaan head CT-scan. Kejadian medication error ditetapkan dengan 
cara menilai kesesuaian atau ketepatan terapi pada pengobatan pasien stroke dengan guideline stroke. Guideline stroke yang digunakan dalam penelitian ini salah satunya adalah PERDOSSI 2011. Pada fase prescribing ketepatan pengobatan meliputi obat yang diresepkan tidak tepat indikasi (ada indikasi tidak ada obat), tidak tepat pasien atau kontraindikasi (tidak sesuai dengan criteria Beer's), tidak tepat obat atau ada obat tidak ada indikasinya, tidak tepat dosis dan aturan pakai, sedangkan pada fase administrasi ketepatan terapi obat secara administrasi yaitu yang berkaitan dengan cara pemberian atau penggunaan obat dan frekuensi. Data instruksi administrasi pemberian obat oleh dokter diambil dari rekam medis sedangkan data pemberian obat oleh perawat diambil dari buku catatan pemberian obat oleh perawat. Dilakukan pencocokan antara tulisan resep tentang perintah administrasi obat di rekam medis dengan catatan pemberian obat oleh perawat. Analisis statistik data karakteristik demografi dan data hasil kajian kejadian medication error disajikan secara deskriptif (persentase).

\section{Analisis Data}

Dilakukan analisa monovariat untuk mengetahui gambaran karakteristik umum pasien (gambaran demografi), karakteristik klinik pasien dan gambaran pengobatan obat. Disamping itu analisis monovariat juga digunakan untuk menggambarkan persentase kejadian medication error. Data frekuensi kejadian pada medication error pada fase prescribing dan administrasi disajikan secara deskriptif.

\section{HASIL DAN PEMBAHASAN \\ Karakteristik umum}

Karakteristik umum pasien meliputi usia, jenis kelamin, pendidikan, dan pekerjaan yang disajikan pada Tabel I. Penelitian dilakukan di IGD rumah sakit X dengan sampel 106 pasien.

Berdasarkan Tabel I jumlah pasien yang berusia > 60 tahun sebanyak 67 (63,20\%). Pasien perempuan dan laki-laki tidak ada perbedaan jumlah masing-masing 53 pasien. Pasien dengan pendidikan tamatan SD menjadi mayoritas yaitu sebanyak 64 pasien $(60,40 \%)$. Pekerjaan sebagai petani, swasta, dan buruh menempati jumlah terbanyak yaitu 60 pasien $(56,60 \%)$. Faktor perbedaan tingkat pendidikan dan jenis pekerjaan tidak berpengaruh atau tidak ada hungannya dengan kejadian stroke.

Dalam penelitian ini pasien geriatri lebih banyak dari pada pasien non geriatri. Sesuai dengan penelitian yang dilakukan oleh Wibisono (2012) bahwa penderita stroke lebih banyak pada pasien geriatri. Hal tersebut juga sesuai dengan penelitian Goldstein et al., (2006) yang menyatakan bahwa risiko terjadinya stroke meningkat dua kali lipat pada usia setelah 55 tahun.

Pada usia 60 tahun ke atas terjadi proses penuaan yang bersifat universal berupa kemunduran dari fungsi biosel, jaringan, organ, bersifat progesif, perubahan secara bertahap, akumulatif, dan intrinsik. Proses penuaan mengakibatkan terjadinya perubahan pada berbagai organ di dalam tubuh seperti sistem gastrointestinal, sistem genitourinaria, sistem endokrin, sistem immunologis, sistem serebrovaskular, sistem saraf pusat dan sebagainya. Dengan bertambahnya usia maka tidak dapat dihindari terjadinya perubahan kondisi fisik baik berupa berkurangnya kekuatan fisik yang menyebabkan individu menjadi cepat lelah maupun menurunnya kecepatan reaksi yang mengakibatkan gerak-geriknya menjadi lamban. Selain itu timbulnya penyakit yang biasanya juga tidak hanya satu macam tetapi multipel, menyebabkan usia lanjut memerlukan bantuan, perawatan dan obat-obatan untuk proses penyembuhan atau sekadar mempertahankan agar penyakitnya tidak bertambah parah (Depkes, 2006). 
Tabel I. Karakteristik demografi dan klinik pasien

\begin{tabular}{llr}
\hline & Karakteristik & Frekuensi (\%) \\
\hline Usia & $>60$ tahun & 63,20 \\
Jenis kelamin & $<60$ tahun & 36,80 \\
& Laki-laki & 50,00 \\
Pendidikan & Perempuan & 50,00 \\
& Tidak Sekolah & 3,80 \\
& SD & 60,40 \\
& SMP & 14,20 \\
& SMA & 14,20 \\
Pekerjaan & Sarjana & 1,90 \\
& Lain-lain & 5,70 \\
& Tidak Bekerja & 27,40 \\
Kategori stroke & PNS & 5,70 \\
& Wiraswasta & 10,40 \\
Head CT-Scan & Petani, Swasta, Buruh & 56,60 \\
& Stroke non Hemoragik & 85,80 \\
& Stroke Hemoragik & 14,20 \\
& Ya & 29,20 \\
& Tidak & 70,80 \\
\hline
\end{tabular}

\section{Kajian medication error} Tabel II.

Kejadian medication error pada pengobatan stroke di IGD rumah sakit X yang disajikan pada

Tabel II. Kejadian medication error pada pasien

\begin{tabular}{lc}
\hline Kejadian Medication Error & Frekuensi (\%) \\
\hline Ya & 98,10 \\
Tidak & 1,90 \\
\hline
\end{tabular}

Dari Tabel II menunjukkan bahwa 104 pasien $(98,10 \%)$ mengalami kejadian medication errordan yang tidak medication error sebanyak 2 pasien $(1,90 \%)$. Unit Gawat Darurat adalah lokasi yang beresiko tinggi terjadinya kesalahan pengobatan. Instalasi Gawat Darurat (IGD) merupakan unit pelayanan dengan berbagai karakteristik yang unik, seperti tingginya stres pekerjaan, aktivitas selama 24 jam, pengambilan keputusan dan prosedur secara individual, banyaknya obat yang tersedia dan terbatasnya tinjauan pengobatan oleh farmasis. Sementara itu pasien yang dilayani di IGD memiliki karakteristik pasien dengan risiko tinggi, pengobatan dengan risiko tinggi, dan keterbatasan riwayat pasien (Jennet, 2006).

Medication error merupakan salah satu penyebab error yang signifikan di IGD. Prevalensi tertinggi dari medical errors yang dapat dicegah juga terdapat di IGD. Studi adverse drug event yang dilaporkan dalam data base nasional menunjukkan bahwa medication error di IGD dua kali lipat dari insiden di rawat inap (Fairbanks, 2007).

Tabel III. Status medication error fase prescribing

\begin{tabular}{lc}
\hline Status ME Fase Prescribing & Frekuensi $(\boldsymbol{\%})$ \\
\hline Ya & 98,10 \\
Tidak & 1,90 \\
\hline
\end{tabular}

Tabel III menunjukkan bahwa sebanyak 104 (98,10\%) mengalami medication error di fase prescribing. Fase ini meliputi obat yang diresepkan tidak tepat indikasi (ada indikasi tidak ada obat), tidak tepat obat atau ada obat yang tidak ada indikasinya, tidak tepat dosis dan aturan pakai. 
Contohnya pemberian vitamin $\mathrm{K}$ yang kurang tepat diberikan pada pasien stroke hemoragik. Berdasarkan hasil observasi yang dilakukan Perwitasari (2010), dari 226 medication errors, 99,12 \% adalah prescribing errors. Berdasarkan data di atas dapat diketahui bahwa angka kejadian medication errors masih sering terjadi di rumah sakit di Indonesia.

Tabel IV. Status medication error fase administrasi

\begin{tabular}{lc}
\hline Status ME Fase Administrasi & Frekuensi (\%) \\
\hline Ya & 61,30 \\
Tidak & 38,70 \\
\hline
\end{tabular}

Dari Tabel IV menunjukkan bahwa pasien yang mengalami kejadian medication error fase administrasi (ketidaksesuaian cara pemberian obat) sebanyak $65(61,30 \%)$ pasien. Ketidaksesuaian cara pemberian piracetam terjadi pada kasus ini. Berdasarkan PERDOSSI 2004, cara pemberian piracetam dengan bolus sedangkan pada kasus ini piracetam diberikan dengan cara intravena. Penelitian yang dilakukan oleh Ong di rumah sakit Selayang di Malaysia pada tahun 2007 menyatakan bahwa terjadi medication error pada fase preparasi dan administrasi sebanyak 97,70\%. Pada fase administrasi sering terjadi kesalahan dikarenakan perintah atau resep yang dituliskan oleh dokter kurang lengkap, salah satu contohnya peresepan obat injeksi tidak ada keterangan intravena ataupun bolus. Selain itu tidak adanya petugas farmasi di ruangan yang menyebabkan perawat yang harus menyiapkan obat-obatan untuk pasien.

Jumlah kejadian ME yang sangat tinggi akan berpengaruh pada kondisi pasien salah satunya akan menyebabkan lama rawat yang menjadi lebih lama, cacat atau bahkan meninggal dunia. Kejadian ME pada pasien stroke juga dipengaruhi oleh sarana dan prasarana dari rumah sakit. Ketersediaan head CT-Scan merupakan standar dalam menentukan ketepatan diagnose stroke yang akan mempengaruhi pola pengobatan selanjutnya.

\section{KESIMPULAN}

Dari hasil penelitian yang telah dilakukan dapat diambil kesimpulan dari 106 pasien jumlah pasien yang berusia > 60 tahun sebanyak 67 pasien $(63,20 \%)$. Dalam penelitian ini sebanyak 85,80\% pasien didiagnosa stroke non hemoragik dan sisanya sebanyak 14,20\% didiagnosa stroke hemoragik. Medication error di fase prescribing sebanyak $98,10 \%$, medication error di fase administrasi sebanyak $61,30 \%$.

\section{DAFTAR PUSTAKA}

Anonim, 1993, ASHP Guidelines on Preventing Medication Errors in Hospital, Am. J. Hosp. Pharm., 50:305-14.

Anonim, 2006, Penggunaan Obat Rasional, Departemen Kesehatan RI, Jakarta.

Anonim, 2009, Standar Instalasi Gawat Darurat, Kepmenkes 856/Menkes/SK/IX/2009.

Anonim, 2013, Pedoman Pengendalian Stroke, Kementrian Kesehatan Republik Indonesia, Jakarta.

Cochen, Michael R., 1991, Medication Error, American Pharmacist Acociation.

Fairbanks RJ. The Emergency Pharmacist: Safety Measure in Emergency Medicine (Justi-fication Summary Document) [internet]. Dec 2007 (cited 2009). Av ailable from: http://www.emergencypharmacist.org

Goldstein L.B., Adams R., Alberts M.J., Appel L.J., Brass L.M., Bushnell C.D., Culebras A., De Graba T.J., Gorelick P.B., Guyton J.R., Hart R.G., Howard G., Hayes M.K., Nixon J.V., Sacco R.L., 2006, Primary Prevention of Ischemic Stroke. Stroke AHA, 37:1583-633.

Harsono, DSS., 2007, Gambaran Umum tentang Gangguan Peredaran Darah Otak : Kapita Selekta Neurologi, UGM Press, Yogyakarta. 
Jennet AM. Pharmacists as A Mean of Cost Containment on The Emergency Department. Paper presented at: American Society of Health-System Pharmacists Mid-Year Clinical Meet-ing, Anaheim, CA. December 6, 2006.

Kohn,L.T.,Corrigan,J.M.,Donaldson,M..S., 2000, Error in Health Care: A Leading Cause of Death and Injury dalam Kohn,L.T., To Err is Human,Institute of Medicine, 26-47, National Academy Press, Washington D.C.

Mutmainah, N., 2008, Kajian Medication Error pada Kasus Stroke Di RS X Surakarta Tahun 2004, Jurnal Farmasi Indonesia, 4(1): 42-46.

Ong, WM., et.al.,2013. Medication Errors in Intravenous Drug Preparation and Administration. Med J Malaysia, 68(1) February 2013.

Patanwala, AE., Warholak TL, Sanders AB, Erstad BL., A prospective observational study of medication errors in a tertiary care emergency department. Ann Emerg Med 2010 Jun, 55(6):522-6.

Perdossi, 2004, Guideline stroke. Jakarta: Perhimpunan Dokter Spesialis Saraf Indonesia.

Perdossi, 2011, Guideline stroke. Jakarta: Perhimpunan Dokter Spesialis Saraf Indonesia.

Perwitasari, D.A., Abror, J., Wahyuningsih, I., 2010, Medication Errors In Outpatients of A Government Hospital in Yogyakarta Indonesia, International Journal of Pharmaceutical Sciences Research and Review, I (1):8-10.

Riskesdas, 2007, Laporan Nasional Riskesdas. Jakarta: Badan Penelitian dan Pengembangan Kesehatan Departemen Kesehatan RI, Hal: 110-118.

Siregar, Charles J.P. dan Endang Kumolosasi., 2006, Farmasi Klinik Teori dan Penerapan, Buku Kedokteran EGC, Jakarta.

Wibisono D.H., 2011, Hubungan Antara Stroke Iskemik Akibat Dislipidemia dan Lokasi Infark di Rsud dr. Moewardi di Surakarta. Fakultas Kedokteran. Universitas Muhammadiyah Surakarta. 
